\title{
Diagnosis and management of pulmonary embolism in pregnancy
}

\author{
SARAH BRODER MD, PETER PARÉ MD \\ Department of Medicine, Respiratory Division, University of British Columbia, \\ Vancouver, British Columbia
}

\begin{abstract}
S BRODER, P PARÉ. Diagnosis and management of pulmonary embolism in pregnancy. Can Respir $\mathbf{J}$ 1996;3(3):187-191.

Pulmonary embolism in pregnancy is a significant and under-recognized problem. In British Columbia, where there are 46,000 pregnancies per year, it is estimated that there are approximately 160 pulmonary embolisms per year and one maternal death every two years secondary to pulmonary embolism. A complete assessment for suspected pulmonary embolus can be performed without putting the fetus at significant risk from radiation exposure. An algorithm is provided for the workup of pulmonary embolus during pregnancy. Heparin is the drug of choice for anticoagulating pregnant women, initially managing the situation with intravenous heparin and then switching to the subcutaneous route given in a bid or tid regimen, aiming to keep the activated partial thromboplastin time 1.5 to 2 times the control. The risks to both the fetus and the mother from anticoagulation during pregnancy are reviewed.
\end{abstract}

Key Words: Anticoagulation, Lung scans, Pregnancy, Pulmonary angiography, Pulmonary embolism

$\mathrm{P}$ ulmonary embolism is a significant and under-recognized source of mortality and morbidity for pregnant women $(1,2)$. The mortality from pulmonary embolism in pregnancy in the United States from 1982 to 1985 was 1.2 deaths per 100,000 live births (1). This represents $12.5 \%$ of all maternal deaths and is the second leading cause of death behind trauma. The incidence of pulmonary embolism is increased 3.5-fold in Blacks and non-Caucasians, and the risk increases with age, being 10 times greater in women over the age of 40 years compared with women under $25(1,2)$.

\section{Diagnostic et prise en charge de l'embolie pulmonaire pendant la grossesse}

RÉSUMÉ : L'embolie pulmonaire pendant la grossesse représente un problème considérable et insuffisamment reconnu. En Colombie-Britannique, sur 46000 grossesses par année, le nombre d'embolies pulmonaires est estimé à environ 160 et le nombre de décès maternels secondaires à une embolie pulmonaire à 1 tous les deux ans. Une évaluation complète peut être faite en cas de suspicion d'embolie pulmonaire sans exposer le foetus à des risques importants de radiations. Un algorithme est proposé pour l'évaluation de l'embolie pulmonaire pendant la grossesse. L'héparine reste l'anticoagulant de choix pour une femme enceinte; cet anticoagulant sera initialement administré par voie intraveineuse puis, par voie sous-cutanée suivant un régime de deux ou trois fois par jour, pour maintenir le temps de céphaline activé de 1,5 à 2 fois le temps témoin. Les risques associés à l'administration d'anticoagulants pendant la grossesse, pour la mère et le foetus, sont passés en revue.

The true incidence of pulmonary embolism during pregnancy can only be estimated from the knowledge of the incidence of proven deep venous thrombosis (DVT). The incidence of DVT in pregnancy was found to be seven per 1000 consecutive ambulatory pregnant women in an out-patient group who had DVT proven by venography or plethysmography (3). Since it has been shown that approximately $50 \%$ of patients who have proven DVT develop pulmonary emboli, based on high probability ventilation/perfusion ( $\dot{\mathrm{V}} / \dot{\mathrm{Q}})$ scans (4), these data imply approximately 3.5 pulmo- 


\begin{tabular}{|c|c|}
\hline Procedure & $\begin{array}{c}\text { Estimated fetal radiation } \\
\text { exposure (rads) }\end{array}$ \\
\hline Chest x-ray & $<0.001$ \\
\hline \multicolumn{2}{|l|}{ Ventilation lung scan } \\
\hline using ${ }^{133} \mathrm{Xe}$ & $0.004-0.019$ \\
\hline using ${ }^{99 m}$ Tc-DTPA & $0.007-0.035$ \\
\hline using ${ }^{99 \mathrm{~m}} \mathrm{Tc} \mathrm{SC}$ & $0.220-0.260$ \\
\hline \multicolumn{2}{|l|}{ Perfusion lung scan using ${ }^{99 m} \mathrm{Tc}-\mathrm{MAA}$} \\
\hline $3 \mathrm{mCi}$ & 0.018 \\
\hline $1-2 \mathrm{mCi}$ & $0.006-0.012$ \\
\hline Limited venography & $<0.050$ \\
\hline $\begin{array}{l}\text { Unilateral venography without } \\
\text { abdominal shield }\end{array}$ & 0.314 \\
\hline${ }^{125}$ I-fibrinogen leg scanning & 2.000 \\
\hline Pulmonary angiography via brachial & $<0.050$ \\
\hline Pulmonary angiography via femoral & $0.211-0.374$ \\
\hline
\end{tabular}

Data summarized from reference 6

nary embolisms per 1000 pregnancies. In British Columbia, with a population of 3.6 million and an estimated rate of 46,000 pregnancies per year, this would mean approximately 160 episodes of pulmonary embolism per year and one death from pulmonary embolism every two years (based on 1.2 deaths per 100,000 live births [1]).

\section{RISK FACTORS FOR THROMBOEMBOLIC DISEASE}

Why are women at an increased risk of thromboembolic disease? Considerable evidence suggests that pregnancy is a hypercoagulable state. Factors that contribute to this hypercoagulable state include the following: venous stasis secondary to the gravid uterus, which obstructs drainage from the legs; increases in nearly all clotting factors, with the exception of factors XI and XIII, as well as increases in soluble fibrin monomer complexes (5) - all of this indicates an activation of the coagulation system which shortens both the prothrombin time and the activated partial thromboplastin time (aPTT); some authors have also observed decreases in the natural anticoagulants antithrombin III and protein S (5); and as pregnancy progresses, there is a steady decrease in the plasma fibrinolytic activity (5) - this hypercoagulable state does not return to the prepregnant levels until six weeks postpartum.

\section{RADIATION RISKS TO FETUS}

A major problem a clinician faces when presented with a pregnant woman in whom pulmonary embolism is suspected is how much radiation is safe for the mother and the fetus. In 1989, Ginsberg et al (6) reviewed the literature with respect to fetal risk from radiation in the diagnosis of pulmonary emboli and DVT in pregnant women. They showed that if the mother received less than 5 rads of radiation during a pregnancy there was a small but statistically significant increased risk of childhood cancer. Depending on the study, the relative risk ranged from 1.2 to 2.4 ; however, the data they reviewed did not allow them to construct a dose-response curve to determine whether there was a linear relationship of exposure to risk. It is important to note that the data they reviewed was from retrospective cohort studies and that the principal procedure associated with radiation exposure was pelvimetry, which would tend to result in exposures nearer to 5 than $1 \mathrm{rad}$. Also, the risk of childhood cancer in the general population in the first 10 years of life is $0.1 \%$ so that the absolute increase in risk is small. There was no increased risk of in utero death, infant death, growth retardation or mental retardation, although there was a slight increase in risk of eye abnormalities. Table 1 shows the radiation exposure associated with a number of common radiological and nuclear medicine procedures (6). Of considerable interest was the observation made by these investigators that the amount of radiation associated with the same procedure varied by up to 10-fold among radiology procedure rooms within the same institution and among institutions.

\section{DIAGNOSING PULMONARY EMBOLISM IN PREGNANCY - VENTILATION/PERFUSION SCANS}

Pregnant women have been excluded from all the major studies to evaluate methods and algorithms for the diagnosis of pulmonary embolism $(7,8)$. However, it is likely that the results can be generalized to the investigation of pulmonary embolism in pregnancy (Figure 1). A major lesson that was learned from the PIOPED (Prospective Investigation of Pulmonary Embolism Diagnosis) study, in which V/ $\dot{Q}$ scans were compared with pulmonary angiograms, was that only $13 \%$ of people who are suspected of having pulmonary embolism have a high probability scan and only $14 \%$ have a normal scan, leaving $73 \%$ with an indeterminant scan (Table 2). This means that using a $\dot{\mathrm{V}}$ / $\dot{Q}$ scan alone achieves a diagnosis in only $27 \%$ of people. If one has a high or intermediate clinical suspicion of a pulmonary embolus, it is very important to go on to a second study if the scan is indeterminant.

The logical next test is to examine the deep veins of the legs, since a positive study for DVT will preclude the need for a pulmonary angiogram and reduces the performance of angiography by $50 \%$ (9). Many methods exist for evaluating the lower extremities. However, radiolabelled fibrinogen leg scanning is completely contraindicated in pregnant women for two reasons: fibrinogen scans give approximately 2 rads of radiation to the fetus - an unacceptably high dose; and fibrinogen scans use ${ }^{125}$ I which accumulates in fetal thyroid tissue, predisposing to congenital hypothyroidism.

Impedance plethysmography (IPG) is the only method for diagnosing deep venous thrombosis in pregnant women that has been proven to be effective (10). Performing the IPG in the lateral decubitus position has been shown to be effective in diagnosing deep venous thrombosis in all three trimesters of pregnancy and is also sensitive in the diagnosis of iliac thrombosis. Duplex ultrasound and venography have not been evaluated in a rigorous manner during pregnancy and they have been reported to have pitfalls. It has been suggested that duplex ultrasound could miss isolated iliac thrombosis in the 


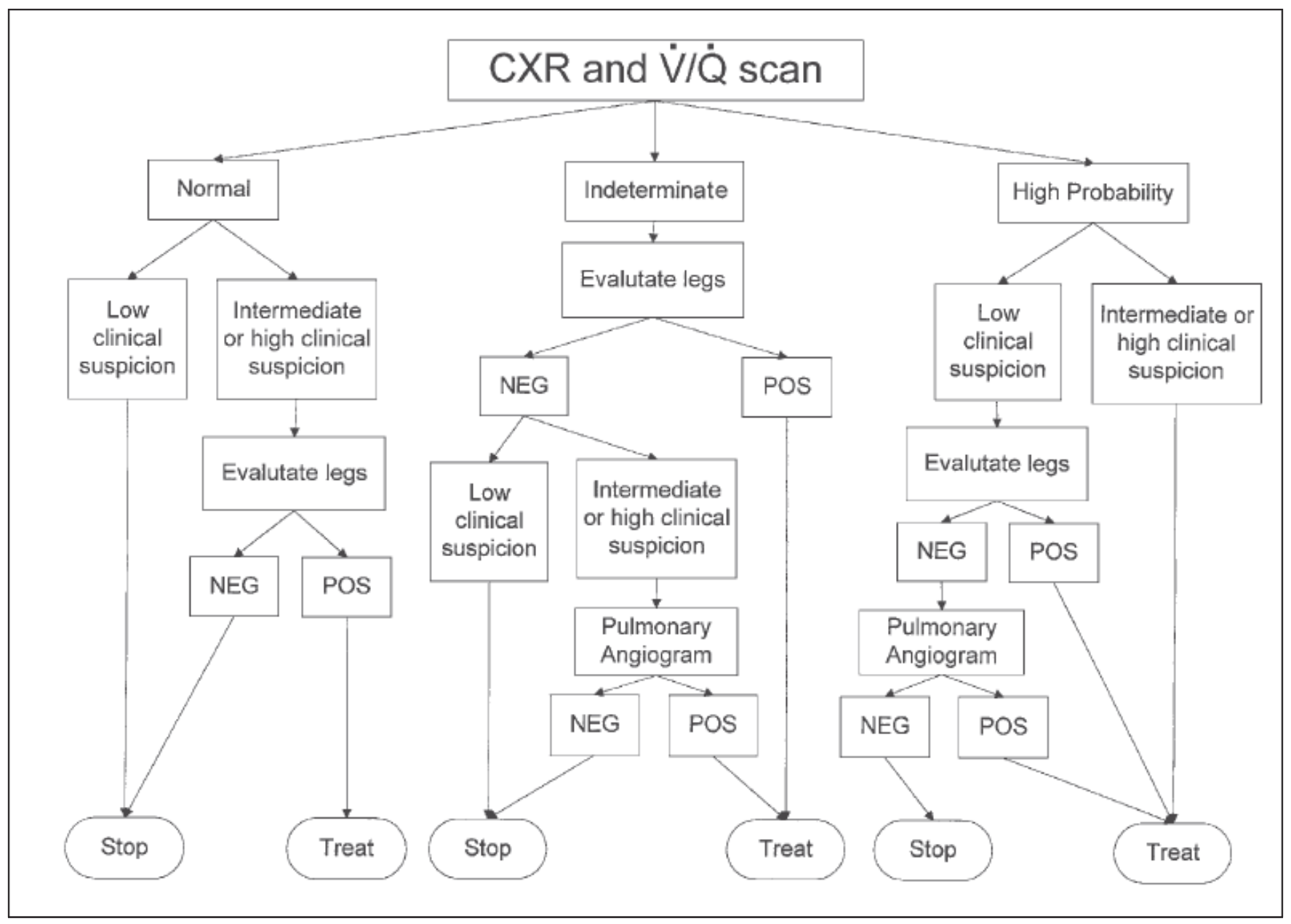

Figure 1) Clinical suspicion of pulmonary embolus. CXR Chest $x$-ray; $\dot{V}$ / $\dot{Q}$ Ventilation/perfusion. Modified from reference 9

third trimester of pregnancy. Venography has produced false positive results in the third trimester secondary to the enlarged uterus and fetal head producing pseudothrombosis on radiographic images of the veins of the lower extremities (11).

For reasons that are unclear, DVT in pregnant women occurs predominantly in the left leg $(3,12)$. In one study, 58 of 60 occurred in the left leg only and two of 60 occurred bilaterally (12). None of the pregnant women had an isolated right DVT. The authors speculated that compression of the left iliac vein by the right iliac artery as they cross may be a contributing factor. Also, the incidence of thrombosis appears to be fairly equally spread across all three trimesters $(3,12)$. Thus, a swollen left leg in the first two trimesters of pregnancy should be fully investigated for DVT and should be considered in the differential in the third trimester along with more benign conditions commonly seen then.

\section{PULMONARY ANGIOGRAPHY}

Pulmonary angiography remains the gold standard for the diagnosis of pulmonary embolus. The dose of radiation to the fetus, if angiography is done through the brachial artery, is less than 0.05 rads. Stein et al (13) reviewed the risks of a pulmonary angiogram and summarized the outcomes from the 1111 angiograms that were done in the PIOPED study (7).
TABLE 2

Chance of pulmonary emboli proven on pulmonary angiogram based on clinical suspicion and ventilation/ perfusion scan results - summary of PIOPED results

\begin{tabular}{lccc}
\hline Scan result & \multicolumn{3}{c}{ Clinical suspicion } \\
\hline High & $96 \%(28 / 29)$ & $88 \%(70 / 80)$ & $56 \%(5 / 9)$ \\
Indeterminate & $59 \%(33 / 56)$ & $22 \%(96 / 427)$ & $9 \%(15 / 158)$ \\
Normal & $0 \%(0 / 5)$ & $6 \%(4 / 62)$ & $2 \%(1 / 61)$ \\
\hline
\end{tabular}

PIOPED Prospective Investigation of Pulmonary Embolism Diagnosis

They found that the risk of death was $0.05 \%$ with major complications having a $1 \%$ incidence. Major complications were defined as the need for cardiopulmonary resuscitation, respiratory arrest requiring intubation or renal failure requiring dialysis. Minor complications occurred in 5\% of people and included respiratory distress not requiring intubation, renal impairment not requiring dialysis, angina, hypotension, congestive heart failure, urticaria, hematoma and arrhythmias.

The radiation exposure for the various tests used in the diagnosis of pulmonary embolism is shown in Table 3 . A chest x-ray and a high probability $\dot{V}$ / scan exposes the fetus to only 0.063 rads of radiation. If the scan is indeterminate and a venogram and pulmonary angiogram are subsequently done, 
TABLE 3

Total radiation to diagnose pulmonary embolism

\begin{tabular}{lc}
\hline Test & Exposure (rads) \\
\hline Chest x-ray + $\dot{V} /$ Q scan & 0.036 \\
Chest x-ray $+\dot{V} /$ Q scan + angiogram & 0.086 \\
Chest x-ray $+\dot{V} /$ Q scan + venogram & 0.365 \\
$\quad$ with abdominal shield & \\
Chest x-ray + $\dot{V} /$ Q scan + venogram & 0.714 \\
$\quad$ without abdominal shield & \\
$\dot{V} / \dot{Q}$ Ventilation/perfusion &
\end{tabular}

$\dot{V} / Q$ Ventilation/perfusion

the total radiation exposure is still only 0.714 rads. Thus, a complete investigation can safely be performed so as not to incorrectly label a young woman with the diagnosis of pulmonary embolism and subject both her and the fetus to the potential risks of long term anticoagulation.

\section{ANTICOAGULATION IN PREGNANCY}

Heparin is the anticoagulant of choice for pregnant women (14). The initial management of a DVT or pulmonary embolism is a continuous infusion of heparin. Rapid heparinization is the most important goal. In a recent report, Raschke et al (15) showed that the use of a weight-based nomogram resulted in significantly faster achievement of therapeutic heparinization. They used a bolus of 80 units $/ \mathrm{kg}$ and then 18 units $/ \mathrm{kg} / \mathrm{h}$. Under this regimen, $80 \%$ of patients were fully anticoagulated within $8 \mathrm{~h}$ whereas, with a standard protocol of 5000 units and then 1000 units/h, only $40 \%$ of patients were similarly anticoagulated at $8 \mathrm{~h}$. This difference was significant $(\mathrm{P}<0.001)$.

Warfarin is not recommended during pregnancy (14). If used between six and 12 weeks of gestation, there is a $26 \%$ incidence of stippled epiphyses and nasal hypoplasia in the fetus (16). It has also been associated with fetal central nervous system abnormalities if given during the second and third trimester.

Anticoagulation for the remainder of pregnancy should be with subcutaneous heparin once a stable dose of intravenous heparin, resulting in an aPTT of 1.5 to 2 times the control for five to 10 days, has been achieved. The initial dosing of subcutaneous heparin is derived by adding up the $24 \mathrm{~h}$ intravenous dose and dividing this into bid or tid doses. The goal should be an aPTT of 1.5 to 2 times control at the midpoint between doses (14). The heparin requirements may increase over the course of the pregnancy because of a decrease in maternal antithrombin 3 levels $(3,17)$. The aim is to treat until six weeks postpartum or a total of three months of anticoagulation if the pulmonary embolism occurs in the latter part of pregnancy. Once the baby is delivered, warfarin is safe because it does not enter breast milk (14).

\section{RISKS TO THE FETUS FROM HEPARIN DURING PREGNANCY}

The potential complications of heparin therapy for the fetus have been recently reviewed $(16,18)$. When the outcomes of pregnancies requiring anticoagulation were compared with pregnancy in the Canadian general population, there was a small increase in still births and neonatal deaths in the former group, but these complications were not significantly more common than in the general population.

\section{RISKS TO THE MOTHER FROM HEPARIN DURING PREGNANCY}

Bleeding complications: A major concern is whether there is an increased risk of maternal hemorrhage with heparin use. In a retrospective cohort study, Ginsberg et al (18) reviewed the complications of heparin therapy in 100 pregnancies in 77 women. Their definition of hemorrhage was very broad and included bleeding from any site. They reported two significant episodes of bleeding producing an incidence of $2 \%(95 \%$ CI 0 to $7.1 \%$ ). Neither episode was associated with significant maternal or fetal complications. This incidence of hemorrhage is similar to the $1.8 \%$ reported by Hull et al (19) when heparin in adjusted dose was used for anticoagulation of nonpregnant patients.

Anderson et al (20) raised the concern that the anticoagulant effect of heparin is prolonged around the time of delivery, making epidural analgesia unsafe. They studied 11 pregnancies in 10 women receiving adjusted dose heparin. They showed that in six pregnancies the anticoagulant effect lasted for up to $28 \mathrm{~h}$ after the last injection of heparin. Four women were unable to have epidural anesthesia secondary to prolongation of the aPTT and one had a complicated delivery with a significant postpartum bleed resulting in a decrease in hemoglobin to $59 \mathrm{~g} / \mathrm{L}$. The mechanism responsible for this prolongation of the aPTT is not clear but it is suggested that women requiring subcutaneous heparin at the time of delivery should have an elective induction of labour after heparin is discontinued for $24 \mathrm{~h}(14,20,21)$. If there is high risk of acute pulmonary embolism, the mother should be switched to intravenous heparin and labour induced $6 \mathrm{~h}$ after the last heparin dose or after reversing the anticoagulation judiciously with protamine sulphate.

Heparin-induced osteoporosis: Long term heparin therapy is associated with osteoporosis. In a number of studies, investigators have examined the effect of sustained heparin use on bone density in pregnant women (22-26). There is a reduction in bone density measured by plain x-rays of the spine and/or hip $(23,24)$ as well as by single/dual photon absorbtiometry $(22,25)$. However, the clinical relevance of the reports is difficult to determine because, in some studies, examination was only done if the patient was symptomatic (23). Dahlman (23) found four of $184(2.2 \%)$ women developed osteoporotic compression fractures of the lower thoracic or lumbar spine. One patient had only been on heparin for seven weeks at $15,000 \mathrm{U} /$ day. In other studies, the finding of decreased bone density was without any clinically significant sequelae. There are no long term follow-up studies to examine how these women do beyond the three-year mark (23-25). It is encouraging to know, however, that repeat studies done six to 12 months after heparin therapy was stopped showed no sustained differences in bone density when all cases enrolled in the study were considered $(22,24)$. In none of the studies was there a demonstrable dose-response relationship between 
heparin dose or duration of treatment and the risk of developing radiographic osteoporosis $(24,25)$.

\section{MANAGEMENT OF PREGNANT WOMEN WITH PREVIOUS THROMBOEMBOLISM}

It is felt that women who have had a previous thromboembolism, whether this be a DVT or a pulmonary embolism, have a $5 \%$ to $12 \%$ risk of recurrence when pregnant $(27,28)$. Dahlman (23) recently reported a $2.7 \%$ recurrence rate of thromboembolism on heparin prophylaxis (five of 184 pregnant women). However, three of these five women were subsequently found to have hypercoagulable states with protein $\mathrm{C}$ deficiency or anticardiolipin antibodies. The remaining two patients were on subtherapeutic doses for prophylaxis. Consequently, prophylaxis is suggested for women with previous thromboembolism during subsequent pregnancies using between 5000 and $7500 \mathrm{U}$ of heparin subcutaneously twice daily. Heparin levels can be monitored with the 3 $\mathrm{h}$ postsubcutaneous injection (peak level). The aim should be

\section{REFERENCES}

1. Sachs BP, Brown DAJ, Driscoll SG, et al. Maternal mortality in Massachusetts - trends and prevention. N Engl J Med 1987;316:667-72.

2. Franks AL, Atrash HK, Lawson HW, Colberg KS. Obstetrical pulmonary embolism mortality, United States, 1970-1985. Am J Public Health 1990;80:720-2.

3. Bergquist A, Bergqvist D, Hallbook T. Deep vein thrombosis during pregnancy: A prospective study. Acta Obstet Gynecol Scand 1983;62:443-8.

4. Huisman MV, Buller HR, ten Cate JW, et al. Unexpected high prevalence of silent pulmonary embolism in patients with deep venous thrombosis. Chest 1989;95:498-502.

5. Von Hugo R, Graeff, H. Thrombohemorrhagic complications in obstetric patients. In: Colman R, Hirsh J, Marder VJ, Salzman EW, eds. Hemostasis and Thrombosis: Basic Principles and Clinical Practice, 2nd edn. Philadelphia: JB Lippincott Co, 1987:926-41.

6. Ginsberg JS, Hirsh J, Rainbow AJ, Coates G. Risks to the fetus of radiologic procedures used in the diagnosis of maternal venous thromboembolic disease. Thromb Haemost 1989;61:189-96.

7. PIOPED Investigators. Value of the ventilation/perfusion scan in acute pulmonary embolism. JAMA 1990;263:2753-9.

8. Hull RD, Hirsh J, Carter CJ, et al. Diagnostic value of ventilation-perfusion lung scanning in patients with suspected pulmonary embolism. Chest 1985;85:819-28.

9. Stein PD, Hull RD, Saltzman HA, Pineo G. Strategy for diagnosis of patients with suspected acute pulmonary embolism. Chest 1993;103:1553-9

10. Hull RD, Raskob GE, Carter CJ. Serial impedance plethysmography in pregnant patients with clinically suspected deep-vein thrombosis. Ann Intern Med 1990;112:663-7.

11. Ginsberg J, Turner C, Brill-Edwards P, Harrison L, Hirsh J. Pseudothrombosis in pregnancy. Can Med Assoc J 1988;139:409-10.

12. Ginsberg JS, Brill-Edwards P, Burrows RF, et al. Deep vein thrombosis during pregnancy: leg and trimester of presentation. Thromb Haemost 1992;67:519-20.

13. Stein PD, Athanasoulis C, Alavi A, et al. Complications and validity of pulmonary angiography in acute pulmonary embolism. Circulation 1992;85:462-8.

14. Ginsberg JS, Hirsh J. Use of antithrombotic agents during pregnancy. Chest 1992;102:385S-90S. to adjust the heparin dose to a serum concentration of 0.08 to $0.15 \mathrm{IU} / \mathrm{mL}$ (23). Alternatively, serial IPG or duplex ultrasonography at weekly intervals can be used to detect silent proximal vein thrombosis $(5,19,23)$.

\section{SUMMARY}

Pulmonary embolism is a significant cause of maternal mortality and morbidity during pregnancy. Full investigation of pulmonary embolism in pregnancy is appropriate and safe. IPG is the only method of evaluating DVT that has proven to be effective in all stages of pregnancy. Heparin is the anticoagulant of choice during the acute episode and subsequent management is with subcutaneous heparin two to three times daily, aiming to keep the aPTT at 1.5 to 2 times the control. There is no increased risk of maternal bleeding on heparin; however, care must be taken to stop or decrease the heparin at least $24 \mathrm{~h}$ before delivery. There is a risk of osteoporosis with long term heparin use, but the impact of its use in pregnancy is difficult to ascertain.

15. Raschke RA, Reilly B, Guidry JR, Fontana JR, Srinivas S. The weight-based heparin dosing nomogram compared with a "standard care" nomogram. Ann Intern Med 1993;119:874-81.

16. Ginsberg JS, Hirsh J, Turner C, Levine MN, Burrows R. Risks to the fetus of anticoagulation therapy during pregnancy. Thromb Haemost 1989;61:197-203.

17. Demers C, Ginsberg JS. Deep venous thrombosis and pulmonary embolism in pregnancy. Clin Chest Med 1992;13:645-56.

18. Ginsberg JS, Kowalchuk G, Hirsh J, Brill-Edwards P, Burrows R. Heparin therapy during pregnancy: risks to the fetus and mother. Arch Intern Med 1989;149:2233-6.

19. Hull R, Delmore T, Carter D, et al. Adjusted subcutaneous heparin versus warfarin sodium in the long-term treatment of venous thrombosis. N Engl J Med 1982;306:189-94.

20. Anderson DR, Ginsberg JS, Burrows R, Brill-Edwards P. Subcutaneous heparin therapy during pregnancy: a need for concern at the time of delivery. Thromb Haemost 1991;65:248-50.

21. Brien WF, Inwood MJ. Subcutaneous heparin therapy during pregnancy: a need for concern at the time of delivery. Thromb Haemost 1992;67:282.

22. Ginsberg JS, Kowalchuk G, Hirsh J, et al. Heparin effect on bone density. Thromb Haemost 1990;64:286-9.

23. Dahlman TC. Osteoporotic fractures and the recurrence of thromboembolism during pregnancy and the puerperium in 184 women undergoing thromboprophylaxis with heparin. Am J Obstet Gynecol 1993;168:1265-70.

24. Dahlman TC, Lindvall N, Hellgren M. Osteopenia in pregnancy during long-term heparin treatment: a radiological study post partum. Br J Obstet Gynaecol 1990;90:221-8

25. Barbour LA, Kick SD, Steiner JF, et al. A prospective study of heparin-induced osteoporosis in pregnancy using bone densitometry. Am J Obstet Gynecol 1994;170:862-9.

26. Zimran A, Shilo S, Fisher D, Bab I. Histomorphometric evaluation of reversible heparin-induced osteoporosis in pregnancy. Arch Intern Med 1986;146:386-8.

27. Badaracco MA, Vessey MP. Recurrence of venous thromboembolic disease and use of oral contraceptives. BMJ 1974;i:215-7.

28. Tengborn L, Bergqvist D, Matzvsch T, Bergquist A, Hedner U. Recurrent thrombembolism in pregnancy and puerperium. Am J Obstet Gynecol 1989;160:90-4. 


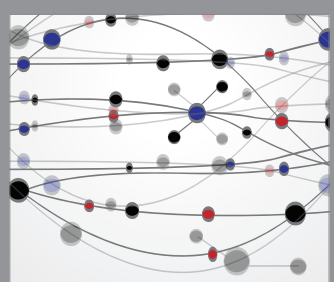

The Scientific World Journal
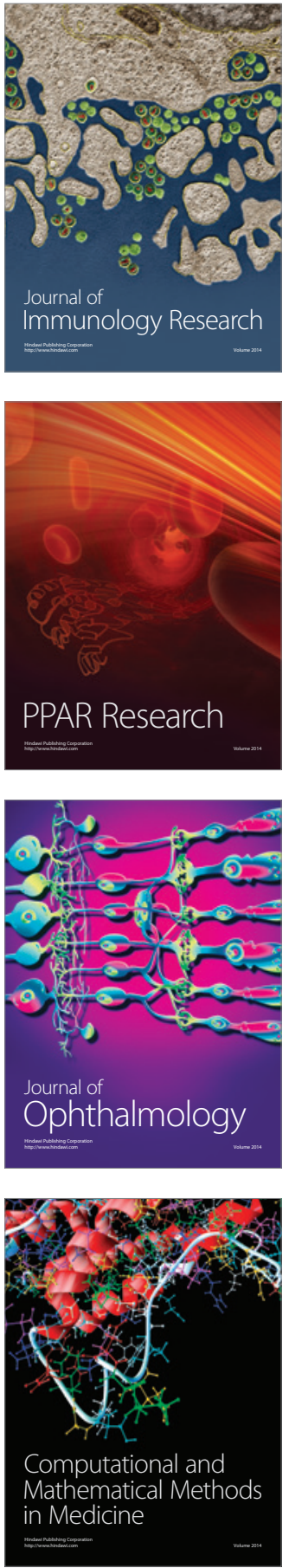

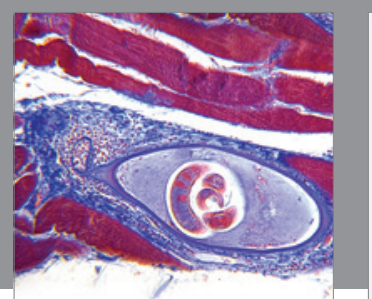

Gastroenterology Research and Practice

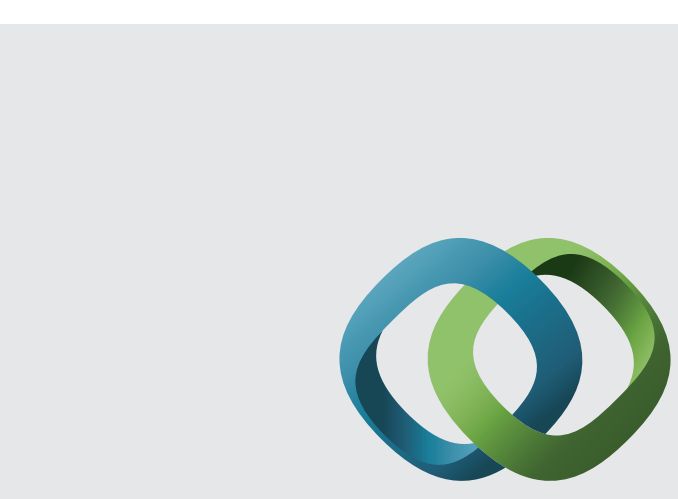

\section{Hindawi}

Submit your manuscripts at

http://www.hindawi.com
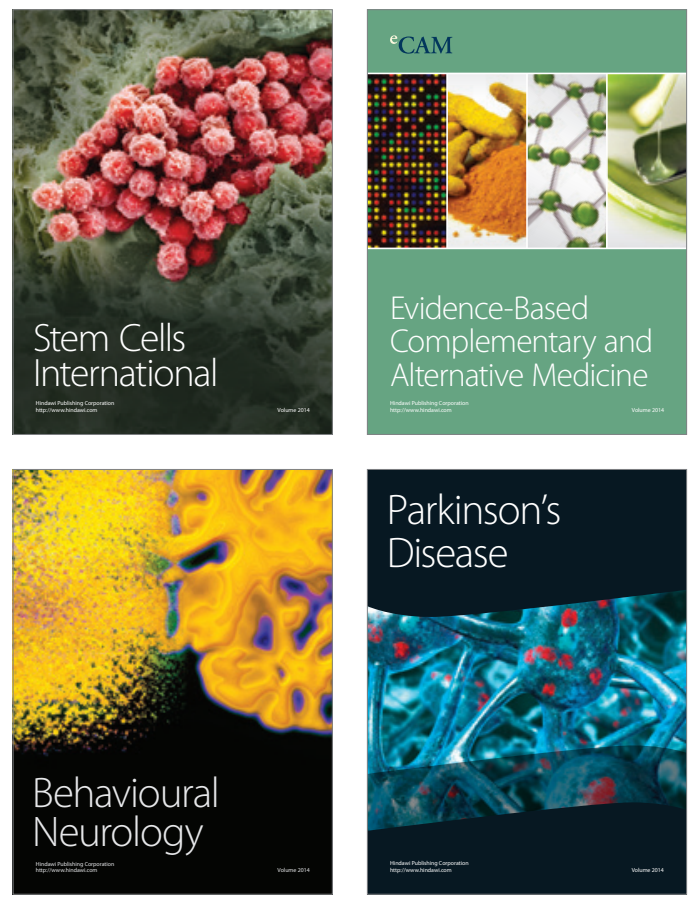
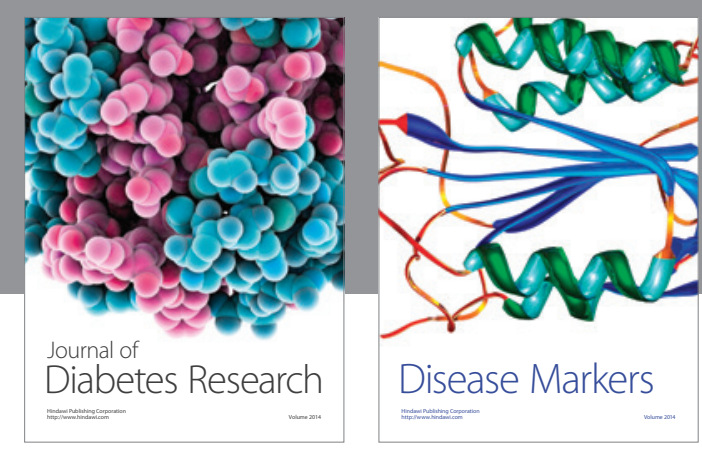

Disease Markers
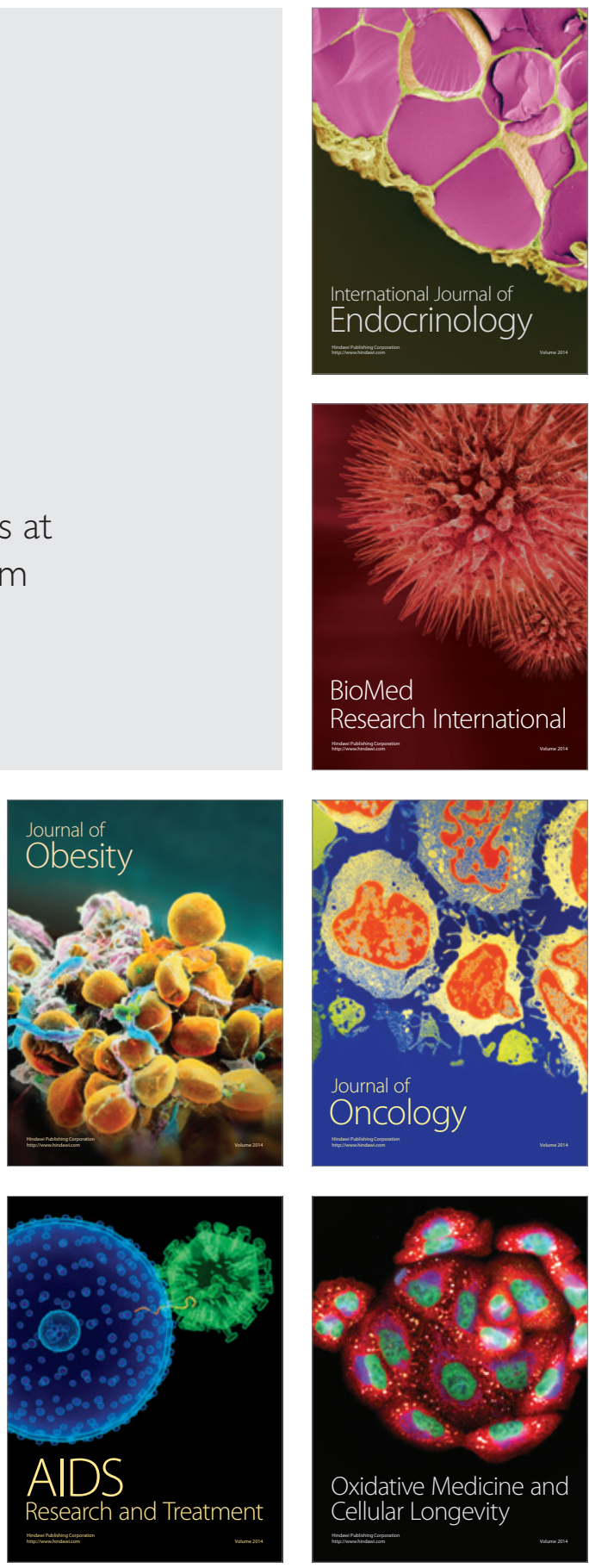